\title{
Cryptococcal granuloma of the frontal lobe in an immunocompromised HIV-negative patient
}

\author{
Rajneesh Misra* ${ }^{*}$, Sushil Kumar and Sandeep Sharma
}

\begin{abstract}
Background: Cryptococcal infection of the brain usually occurs in immunocompromised individuals and manifests with signs and symptoms suggestive of meningoencephalitis. It is rare to come across this infection as a brain granuloma manifesting with focal neurological deficits and without any overt immune deficiency.

Case presentation: A 55-year-old male presented with dysphasia. His vital signs were normal at presentation and he was afebrile. Computed tomography (CT) and MRI (magnetic resonance imaging) suggested left frontal mass lesion. A possibility of a solitary metastasis from an occult primary was considered and contrast-enhanced computed tomography abdomen and chest were done which revealed no significant abnormality. The patient underwent craniotomy and excision of lesion. The excised tissue was soft, greyish and friable. He started to have fever on post-operative day 5, and CSF study was done to rule out post-operative bacterial meningitis. However, the CSF returned positive for cryptococcus. Subsequently, the histopathology report from the excised tissue showed cryptococcal granuloma. He remained an inpatient for 32 days during which he received intravenous amphotericin B and flucytosine along with oral fluconazole. After discharge, he was continued on oral fluconazole for 47 days.

Conclusion: Cryptococcal granuloma of the brain, especially of the frontal lobe, is rare. Its clinical and radiological features mimic that of a neoplastic process. The diagnosis can be especially difficult if the usual pointer for immunosuppression in the form of HIV-positive status is missing. Such cases need operative intervention. However, once the diagnosis is made histologically, it is important to investigate for other causes of immunosuppression as in our case where the patient turned out to be deficient in natural killer cells.
\end{abstract}

Keywords: Cryptococcosis, Granuloma, Immunocompromised HIV-negative

\section{Introduction}

Cerebral cryptococcosis is a deadly fungal infection particularly in elderly patients. Predisposing factors include HIV (human immunodeficiency virus) infection, liver disease [1], diabetes mellitus, malignancy, kidney disease, solid organ transplantation and patients receiving corticosteroids. Recently, we came across a not so old and infirm patient with cryptococcal granuloma mimicking a

* Correspondence: misra_rajneesh@yahoo.com

Department of Neurosurgery, St. Stephen's Hospital, Tis Hazari, Delhi 110054, India brain tumour. This patient was found to be immunocompromised, but was not HIV-positive.

Cryptococcus is an encapsulated yeast-like fungus found in faeces of mammals and birds especially pigeons [2]. It has a worldwide distribution. The infection is acquired through inhalation of droppings and spreads haematogenously to the CNS (central nervous system) [3]. Apart from the lungs, the CNS is affected more commonly because anti-cryptococcal factors present in the serum are absent in CSF [4]. Cryptococcal infections of the brain usually present as meningitis and rarely as cryptococcomas. The commonest parenchymal sites of
Springer Open

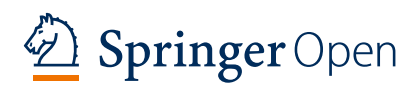

(c) The Author(s). 2020 Open Access This article is licensed under a Creative Commons Attribution 4.0 International License, which permits use, sharing, adaptation, distribution and reproduction in any medium or format, as long as you give appropriate credit to the original author(s) and the source, provide a link to the Creative Commons licence, and indicate if changes were made. The images or other third party material in this article are included in the article's Creative Commons licence, unless indicated otherwise in a credit line to the material. If material is not included in the article's Creative Commons licence and your intended use is not permitted by statutory regulation or exceeds the permitted use, you will need to obtain permission directly from the copyright holder. To view a copy of this licence, visit http://creativecommons.org/licenses/by/4.0/. 
involvement are the midbrain, basal ganglia and choroid plexus though our case had frontal lobe involvement [5].

CNS cryptococcosis is usually caused by Cryptococcus neoformans, and it usually affects patients with immunosuppression and rarely affects immunocompetent patients as well [3]. The major cause of immunosuppression after the onset of AIDS epidemic is HIV. However, prior to this, various other causes like haematological malignancy, solid organ transplant, corticosteroid-induced immunosuppression, sarcoidosis and other causes of $\mathrm{CD} 4^{+}$lymphocyte deficiency used to hold the sway [6]. Investigations to ascertain the cause of decreased host resistance to this common environmental fungus reveal subtle impairments in lymphocyte response to cryptococcal antigen stimulation [7-9].

\section{Case report}

A 55-year-old male was admitted with complaints of progressively increasing difficulty in speaking for the last 3 months and one episode of convulsions a month prior to admission with off and on headache. On examination, his vital signs were within normal limits and he was afebrile. He was conscious and expressive dysphasia was present. The fundus was normal. There were no sensory or motor deficits. He was not a known diabetic. On investigations, routine haemogram, LFT (liver function test) and KFT (kidney function tests) were normal. ELISA (enzyme-linked immunosorbent assay) for HIV was negative. CT revealed an enhancing lesion with central necrosis and peripheral oedema (Fig. 1). MRI demonstrated hypointense lesion on $\mathrm{T} 1$ with hyperintense centre and hypointense ring on T2. There was ring enhancement on contrast (Fig. 2). The possibility of the lesion being a metastasis from an occult primary was considered. He underwent a CECT chest which releveled minimal focal fibrosis and CECT whole abdomen which was showed mild hepatomegaly without any evidence of primary malignancy.

Left frontal craniotomy revealed a well-defined mass, soft to firm, greyish white and with surrounding edema. The mass was excised completely. Histopathology revealed the diagnosis of cryptococcal granuloma. On 5th day of the surgery, the patient started having fever and CSF (cerebrospinal fluid) biochemistry revealed protein $130 \mathrm{mg} \%$, glucose $8 \mathrm{mg} \%$, and 350 cells with $92 \%$ neutrophils, and cryptococcal antigen lateral flow assay was positive. India ink stain of CSF revealed presence of yeast. Immunodeficiency panel revealed natural killer cell deficiency. Patient was treated with amphotericin B, fluconazole and flucytosine for 32 days as an inpatient. Patient responded to treatment and was advised fluconazole for 47 additional days after discharge.

Patient has been followed for over a period of $5^{1 /}{ }_{2}$ years and occasionally gets seizures and is on anticonvulsants.

\section{Discussion}

Clinical presentation of cerebral cryptococcal granuloma mimics brain tumour which confounds the diagnosis. Granuloma formation is rare. Two varieties and five serotypes have been recognised, viz., C. neoformans var neoformans serotypes (A, D, AD) and C. neoformans var gattii (B, C). C. neoformans is more likely to cause disease in immunocompromised hosts, whereas $C$. gattii is implicated in immuonocompetent ones [10, 11]. The variety in our patient was $C$. neoformans. However, further serotyping was not done as it was not available at our institute. Cryptococcoma formation is more common with C. gattii [12]. Clinical features of brain involvement are nonspecific. Raised intracranial tension features characterised by headache, vomiting and later

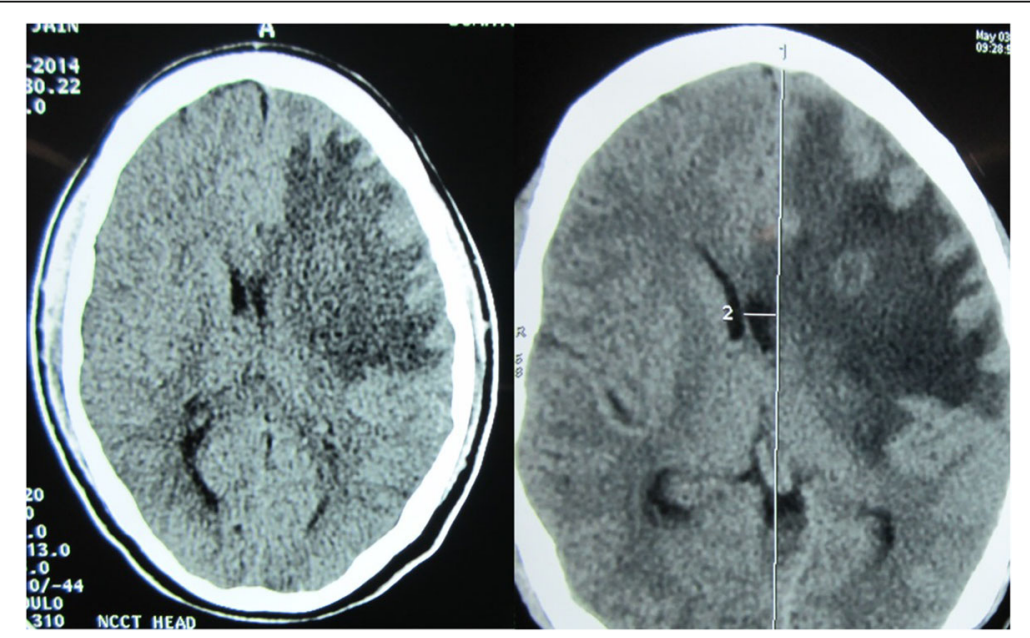

Fig. 1 Computed tomography showing left diffuse oedema in the left frontal region. Right Contrast CT showing thick small ring with central hypodensity surrounded by brain oedema with effacement of frontal horn 


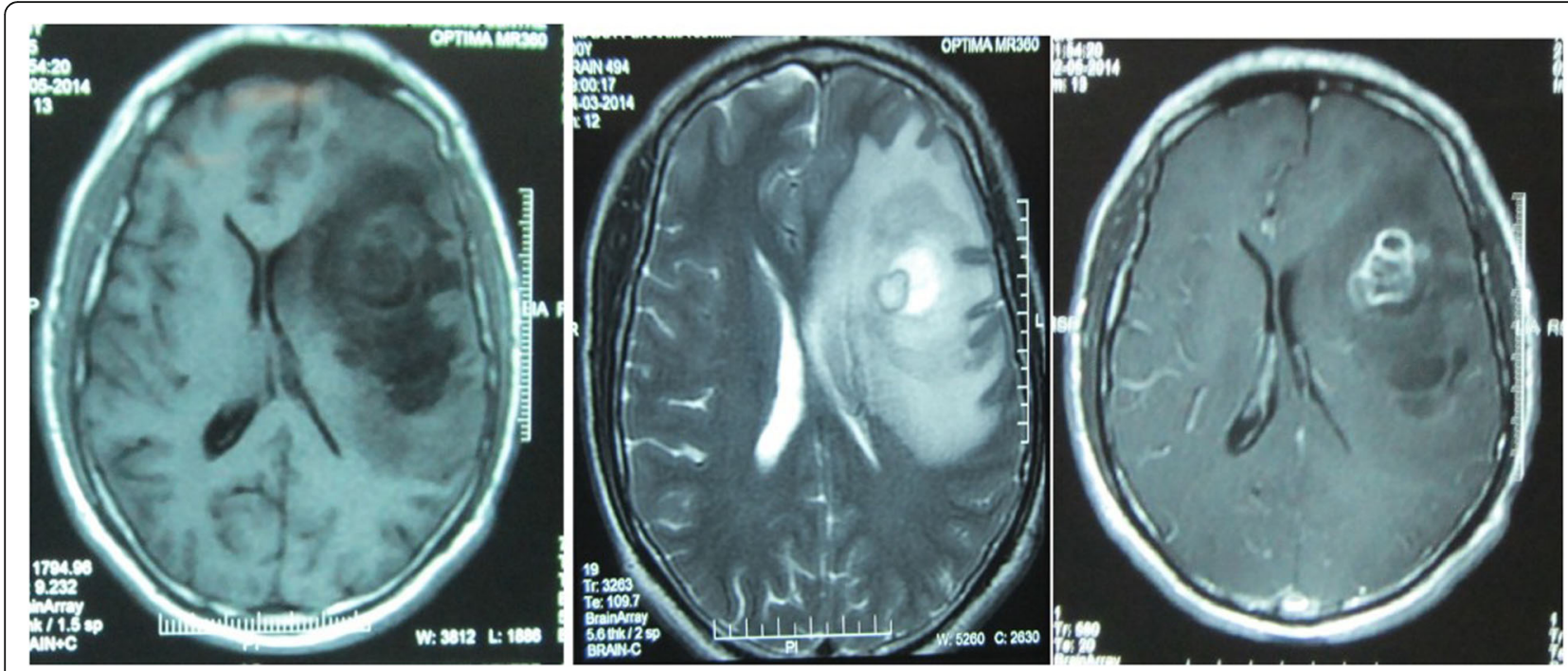

Fig. 2 Magnetic resonance imaging showing left T1WI large hypointense area with effacement of ventricle and middle T2WI showing central small hyperintense area with surrounding hypointense ring and with hyperintense gross oedematous area around right contrast study showing ring-enhancing lesion with central hypointensity

on focal neurological deficit may be seen depending upon the location of the granuloma which was in the form of dysphasia in our patient.

Sparse literature is available about similar cases. Nadkarni et al. [13] reported a case of a 22-year-old patient who presented with focal seizures with secondary generalization. Imaging revealed a peripheral ringenhancing lesion in the left parietal lobe with significant edema. He was started on anti-tubercular regimen and anticonvulsants to which he initially seemed to respond only to have repeat seizures a year later. Repeat imaging revealed increase in edema, and the patient underwent a stereotactic biopsy finally revealing the diagnosis of cryptococcosis. Like in our patient, the diagnosis of cryptococcosis was made only after histopathology and the more common pathology, viz., metastasis in our case and tubercular granuloma in this case were considered first. More importantly, the workup for HIV was negative in both patients.

Qi Zhu et al. [14] reported a case of a 12-month-old child with 6-month history of seizures. Initial workup for seizures revealed bilateral EEG slow wave activity especially in the left occipital region. CT showed irregularly calcified lesion in left parieto-occipital region. MRI demonstrated mixed signals without edema or visible flow voids. It was diagnosed as a vascular malformation. Three years later, when she presented with increased frequency of seizures and underwent an excision of the lesion, it was revealed to be cryptococcal granuloma. This case reinforces the status of cryptococcal granuloma as a great mimic.
Li et al. [15] in 2009 while reviewing the available 17 cases in literature reported their own case of a 49-yearold woman who was clinico-radiologically diagnosed with high grade glioma of the right occipital lobe. Similar to our case, she did not have any meningeal signs, had focal deficit in the form of right homonymous hemianopia and was afebrile. Workup for immune compromise status was negative. However, unlike our case, CSF in her case did not reveal any cryptococci.

Gologorsky et al. [16] reported an African American 12-year-old whose clinical presentation was suggestive of cerebellar lesion and CT and MRI showed ringenhancing right cerebellar lesion suggestive of cerebellar astrocytoma. Excision of lesion revealed it to be cryptococcal granuloma. However, unlike our patient, the child had been febrile at presentation with a fever of $100.9^{\circ} \mathrm{F}$. Similar to our patient, he did not have any papilledema. CT features include hypodense or isodense mass with homogenous and ring-like enhancement after contrast injection. At times, the granuloma may be calcified on CT [14]. MRI is the most sensitive modality for diagnosis of the nature of mass lesion. However, in this case, it offers a large gamut of differentials including metastatic malignancy, lymphoma, toxoplasmosis, tuberculoma, pyogenic abscess and primary CNS malignancy $[15,16]$. On MRI, the lesions appear low intensity on T1WI (T1 weighed imaging) and high intensity on T2WI (T2 weighed imaging). On DWI (diffusion weighed imaging), hypointensity in the central cavity mimics a necrotic brain tumour rather a pyogenic abscess. Contrast enhancement is uncommon in immunocompromised 
patients due to the underlying immunosuppression and non-immunogenic nature of the polysaccharide capsule of the organism [17]. This is well described by Kamezawa et al. [18] in their case in which the CT scan revealed a cystic lesion abutting the right frontal horn. Further evaluation with MRI had suggested a lesion mimicking the CSF intensities on both T1 and T2 images without contrast enhancement. However, the DW-EPI and FLAIR gave a higher signal and a more heterogenous signal on DWI leading to a diagnosis of epidermoid. However, our patient showed contrast enhancement. Taneja et al. had reported a case similar to ours which had presented with raised ICP features, hemiparesis and fever. Imaging had revealed multiple ring-enhancing lesions and CSF had yielded C. neoformans [19]. However, their experience was different from ours in having features of meningitis which prompted them to carry out CSF investigations. Our patient had only raised ICP features and expressive dysphasia with no meningeal signs.

Spectroscopy shows increased lactate along with decrease in NAA ( $N$-acetyl aspartate) suggesting neuronal damage. However, this is a non-specific sign. In their study describing the MRS characteristics of cerebral abscesses of differing aetiologies, Dusak et al. noted the presence of succinate, alanine, lipid and lactate [20]. Histopathology showed characteristic features of a fungal granuloma which consisted mainly of numerous encapsulated fungal spores, lymphocytes, eosinophilic granulocytes, neutrophilic granulocytes, fibroblasts, multinucleated giant cells and multiple calcifications.

Medical management of cerebral cryptococcosis relies upon the use of one of the available form of intravenous amphotericin B and 5-FC for induction followed by consolidation and maintenance with fluconazole [21]. Surgery is necessary for a definitive diagnosis and therapy especially in cases presenting with mass effect. Postoperatively, anti-fungal drugs are used to prevent cryptococcal meningitis [22]. Surgery may also shorten the duration of anti-fungal treatment [23].

\section{Conclusions}

Cryptococcal granuloma of the brain, especially of the frontal lobe, is rare. Its clinical and radiological features mimic that of a neoplastic process. The diagnosis can be especially difficult if the usual pointer for immunosuppression in the form of HIV-positive status is missing. Such cases need operative intervention. However, once the diagnosis is made histologically, it is important to investigate for other causes of immunosuppression as in our case where the patient turned out to be deficient in natural killer cells.

\section{Abbreviations}

CD4: Cluster of differentiation 4; CECT: Contrast-enhanced CT scan; CNS: Central nervous system; CSF: Cerebrospinal fluid; CT: Computed tomography; DWI: Diffusion weighed imaging; ELISA: Enzyme-linked immunosorbent assay; EPI: Echo planar imaging; HIV: Human immunodeficiency virus; ICP: Intracranial pressure; KFT: Kidney function test; LFT: Liver function test; MRI: Magnetic resonance imaging; MRS: MR spectroscopy; NAA: N-Acetyl aspartate; T1Wl: T1 weighed imaging; T2WI: T2 weighed imaging

\section{Acknowledgements}

None

Authors' contributions

All the authors contributed equally for this case report.

\section{Funding}

No funding was obtained for producing this work.

Availability of data and materials

All the patient data is available in the hospital medical records and is available for analysis if required.

Ethics approval and consent to participate

This case report does not require any ethics committee approval.

\section{Consent for publication}

Formal consent has been obtained from the patient for the publication of the case report.

\section{Competing interests}

The authors declare no conflict of interests.

Received: 2 November 2019 Accepted: 17 June 2020

Published online: 30 June 2020

\section{References}

1. Tseng HK, Liu CP, Ho MW, et al. Microbiological, epidemiological, and clinical characteristics and outcomes of patients with cryptococcosis in Taiwan, 1997-2010. PLoS One. 2013;8(4):e61921. Published 2013 Apr 17. https://doi.org/10.1371/journal.pone.00619212.

2. Keohane C, Galvin RJ, Buckley TF. Cryptococcal granuloma of the brain. J Neurol Neurosurg Psychiatry. 1990;53:1107-8.

3. Igel HJ, Bolande RP. Humoral defense mechanisms in cryptococcosis: substances in normal human serum, saliva, and cerebrospinal fluid affecting the growth of Cryptococcus neoformans. J Infect Dis. 1966;116(1):75-83.

4. Garcia CA, Weisberg LA, Lacorte WS. Cryptococcal intracerebral mass lesions: CT-pathologic considerations. Neurology. 1985;35(5):731-4.

5. Liu BX, Dai XJ, Liu H, Gong HH, Wang YX, Zhang LL. Cerebellar cryptococcosis characterised by a space occupying lesion in an immunocompetent non-HIV patient. Neuropsychiatr Dis Treat. 2015;11:21-5.

6. Li M, Chen Z, Xu L, Gan Z, Peng F, Liu J. A comparison of the clinical characteristics and outcomes of cryptococcal meningitis in HIV-negative individuals with and without immunosuppression. Neurologist. 2019;24(1):1-57.

7. Diamond RD, Bennett JE. Disseminated cryptococcosis in man: decreased lymphocyte transformation in response to Cryptococcus neoformans. J Infect Dis. 1973;127(6):694-7.

8. Graybill JR, Alford RH. Cell-mediated immunity in cryptococcosis. Cell Immunol. 1974;14(1):12-21.

9. Schimpff SC, Bennett JE. Abnormalities in cell-mediated immunity in patients with Cryptococcus neoformans infection. J Allergy Clin Immunol. 1975;55(6):430-41

10. Mitchell DH, Sorrell TC, Allworth AM, Heath $\mathrm{CH}$, MCGregor AR, Papanaoum $\mathrm{K}$, et al. Cryptococcal disease of the CNS in immunocompetent hosts: influence of cryptococcal variety on clinical manifestations and outcome. Clin Infect Dis. 1995;20(3):611-6.

11. Speed B, Dunt D. Clinical and host differences between infections with the two varieties of Cryptococcus neoformans. Clin Infect Dis. 1995;21(1):28-34 discussion 5-6. 
12. Chen S, Sorrell T, Nimmo G, Speed B, Currie B, Ellis D, et al. Epidemiology and host- and variety-dependent characteristics of infection due to Cryptococcus neoformans in Australia and New Zealand. Australasian Cryptococcal Study Group. Clin Infect Dis. 2000;31(2):499-508.

13. Nadkarni TD, Menon RK, Desai Kl, Goel A. A solitary cryptococcal granuloma in an immunocompetent host. Neurol India. 2005;53(3):365-7.

14. Zhu JQ, Tao XF, Bao WQ, Hao NX, Wu XR. Calcified cerebral cryptococcal granuloma. Indian J Pediatr. 2013;80(4):345-8.

15. Li Q, You C, Liu Q, Liu Y. Central nervous system cryptococcoma in immunocompetent patients: a short review illustrated by a new case. Acta Neurochir (Wien). 2010;152(1):129-36.

16. Gologorsky Y, DeLaMora P, Souweidane MM, Greenfield JP. Cerebellar cryptococcoma in an immunocompetent child. Case report. J Neurosurg 2007;107(4 Suppl):314-7.

17. Mathews VP, Alo PL, Glass JD, Kumar AJ, McArthur JC. AIDS-related CNS cryptococcosis: radiologic-pathologic correlation. AJNR Am J Neuroradiol. 1992;13(5):1477-86.

18. Kamezawa T, Shimozuru T, Niiro M, Nagata S, Kuratsu J. MRI demonstration of intracerebral cryptococcal granuloma. Neuroradiology. 2000;42(1):30-3.

19. Taneja J, Bhargava A, Loomba P, Dogra V, Thakur A, Mishra B. Cryptococcal granulomas in an immunocompromised HIV-negative patient. Indian J Pathol Microbiol .2008;51(4):553-5,

20. Dusak A, Hakyemez B, Kocaeli H, Bekar A. Magnetic resonance spectroscopy findings of pyogenic, tuberculous, and cryptococcus intracranial abscesses. Neurochem Res. 2012;37(2):233-7.

21. Perfect JR, Dismukes WE, Dromer F, Goldman DL, Graybill JR, Hamill RJ, et al. Clinical practice guidelines for the management of cryptococcal disease: 2010 update by the Infectious Diseases Society of America. Clin Infect Dis. 2010;50:291-322

22. Konovalov AN, Pitskhelauri DI, Korshunov AG, Arutiunov NV, Imshenetskaia VF, Khukhlaeva EA. A cryptococcal granuloma of the midbrain. Zh Vopr Neirokhir Im N N Burdenko. 1999;2:33-6.

23. Ulett KB, Cockburn JW, Jeffree R, Woods ML. Cerebral cryptococcoma mimicking glioblastoma. BMJ Case Rep. 2017;2017:bcr2016218824. Published 2017 Feb 10. doi:10.1136/bcr-2016-218824.

\section{Publisher's Note}

Springer Nature remains neutral with regard to jurisdictional claims in published maps and institutional affiliations.

\section{Submit your manuscript to a SpringerOpen ${ }^{\circ}$ journal and benefit from:}

- Convenient online submission

- Rigorous peer review

- Open access: articles freely available online

- High visibility within the field

- Retaining the copyright to your article

Submit your next manuscript at $\boldsymbol{\nabla}$ springeropen.com 